EXTENDED REPORT

\title{
Thermal stability and structure of cancellous bone mineral from the femoral head of patients with osteoarthritis or osteoporosis
}

\author{
L D Mkukuma, C T Imrie, J M S Skakle, D W L Hukins, R M Aspden
}

Ann Rheum Dis 2005;64:222-225. doi: 10.1136/ard.2004.021329

\begin{abstract}
See end of article for authors' affiliations

.....................

Correspondence to: Professor R M Aspden, University of Aberdeen, Department of Orthopaedic Surgery, Institute of Medical

Sciences, Foresterhill, Aberdeen AB25 2ZD Scotland, UK; r.aspden@ abdn.ac.uk
\end{abstract}

Accepted 1 June 2004
Background: Cancellous bone from patients with osteoarthritis (OA) has been reported to be undermineralised and that from patients with osteoporosis (OP) is more liable to fracture. Changes in the mineral component might be implicated in these processes.

Objectives: To investigate the thermal stability and the mineral structure of cancellous bone from femoral heads of patients with either OA or OP.

Methods: Powdered bone was prepared from femoral heads of patients with either OA or OP and a control group. Composition and thermal stability were determined using a thermogravimetric analyser coupled to a mass spectrometer. Unit cell dimensions and the crystallite size of the mineral were measured using $x$ ray diffraction.

Results: Thermal stability of the bone matrix, or of the mineral phase alone, was little altered by disease, though OA bone contained less mineral than OP or control bone. In all three groups, $x$ ray diffraction showed that the mineral unit cell dimensions and crystallite sizes were the same. The mean carbonate content in the mineral from all three groups was between 7.2 and $7.6 \%$ and is suggested to be located in both the A site (that is, substituting for hydroxyl groups), and the B site (that is, substituting for phosphate groups).

Conclusions: These results confirm that there is a lower mass fraction of mineral in OA bone, and indicate that the nature of the mineral is not a factor in either disease process.

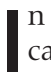
osteoporosis (OP) an exaggerated loss of mainly cancellous bone results in bone fragility and an increased risk of fracture following minimal trauma. The mechanical and material properties of the bone matrix appear to be little different from people of the same age without OP. ${ }^{1-4}$ However, there may be changes in the material properties that have previously been overlooked ${ }^{5}$ and there are reports of alterations in collagen crosslinking that could alter the mechanical properties. ${ }^{6}$

Although osteoarthritis (OA) is traditionally believed to be a disease of articular cartilage, there is increasing interest in the changes occurring in the bone, including the suggestion that these are part of a disorder of the whole joint ${ }^{7}$ or even the whole musculoskeletal system, ${ }^{8}$ rather than secondary to cartilage degeneration. Subchondral bone sclerosis is one of the clinical signs of OA and appears to result from changes in trabecular orientation, thickness, and number, ${ }^{9-11}$ and an expansion of the subchondral bone plate. ${ }^{12}{ }^{13}$ In addition to this proliferation of bone, there is mounting evidence for changes in the bone matrix, ${ }^{2-4}{ }^{14-16}$ even at sites remote from the affected joints. ${ }^{717}$

Previous studies have shown that the cancellous bone from all sites over the femoral head and neck of patients with OA is hypomineralised. ${ }^{2}$ Consequently, it has a reduced material density, confirming earlier studies using a density fractionation method, ${ }^{14}$ and the stiffness increases more slowly with apparent density than does normal or OP bone. ${ }^{2}$ Scanning electron microscopy indicates a more porous texture, similar to that found in woven bone, and greater heterogeneity in mineralisation. ${ }^{16}$ The basis of these material changes is unclear.

The study reported here investigates further the nature of these changes by investigating the extent of mineralisation and the mineral structure of the bone matrix.
Thermogravimetric analysis (TGA) linked to mass spectrometry (MS) was used to investigate the thermal decomposition of the matrix and hence its mineral content and the carbonate content of the mineral. In this combined TGA-MS technique, a sample is heated in a stream of gas, its mass is determined as a function of temperature, and the thermal decomposition products are monitored by mass spectrometry. TGA has been used previously to investigate synthetic apatites $^{18-21}$ and mineral extracted from bovine bone. ${ }^{22}$ The lattice dimensions in the mineral crystals and the crystallite size were measured by $x$ ray diffraction (XRD), which is a standard method for determining these properties in synthetic and natural apatites. ${ }^{23-26}$ The aims of this study were to confirm the mineralisation deficit in OA cancellous bone of the hip and determine whether there were any concomitant changes in the mineral phase.

\section{MATERIALS AND METHODS}

Source of material

Femoral heads were obtained from patients undergoing a hip replacement for either a fractured femoral neck attributed to OP ( 18 patients) or for primary OA of the hip (27 patients). Control bone tissue was obtained from the distal femur from above knee amputations (seven patients), because femoral heads from non-diseased patients proved impossible to obtain. Local ethics committee approval was obtained to use tissue removed during the normal course of surgery and consent was obtained from patients for this purpose. The median ages and the oldest and youngest in each group are shown in table 1 for the various analyses.

Abbreviations: $\mathrm{CHA}$, carbonate hydroxyapatite; MS, mass spectrometry; OA, osteoarthritis; OP, osteoporosis; TGA, thermogravimetric analysis; XRD, $x$ ray diffraction 
Table 1 Details of groups from which bone was removed

\begin{tabular}{|c|c|c|c|}
\hline Group & $\begin{array}{l}\text { No. of } \\
\text { patients }\end{array}$ & $\begin{array}{l}\text { Sex } \\
(M / F)\end{array}$ & $\begin{array}{l}\text { Median age } \\
\text { (oldest, youngest }\end{array}$ \\
\hline \multicolumn{4}{|c|}{ Measurement of crystallite size } \\
\hline Osteoarthritic & 27 & $12 / 15$ & $73(90,50)^{*}$ \\
\hline Osteoporotic & 16 & $4 / 12$ & $86(92,66)^{*}$ \\
\hline \multirow[t]{2}{*}{ Control } & 4 & & $77(93,64)$ \\
\hline & & $p=0.14$ & ${ }^{*} p<0.05$ \\
\hline \multicolumn{4}{|c|}{ Unit cell dimensions } \\
\hline Osteoarthritic & 10 & $0 / 10$ & $73.5(81,60)$ \\
\hline Osteoporotic & 10 & $5 / 5$ & $73.5(87,66)$ \\
\hline \multirow[t]{2}{*}{ Control } & 6 & $2 / 4$ & $71.5(93,56)$ \\
\hline & & $p=0.04$ & $p=0.92$ \\
\hline \multicolumn{4}{|l|}{ TGA } \\
\hline Osteoarthritic & 20 & $8 / 12$ & $73(90,50)^{*}$ \\
\hline Osteoporotic & 18 & $3 / 15$ & $85(92,66)^{*} \dagger$ \\
\hline \multirow[t]{2}{*}{ Control } & 7 & $3 / 4$ & $69(93,37) \dagger$ \\
\hline & & $p=0.23$ & $p<0.05$ \\
\hline
\end{tabular}

Analysis of sex matching was performed using a $\chi^{2}$ test. Age distributions were analysed using one way analysis of variance followed by Tukey's test for pairwise comparisons, when normally distributed, or KruskalWallis one way analysis of variance on ranks if data failed the Kolmogorov-Smirnov test for normality with $p<0.05$ ( $p>0.05$ indicates no significant differences between groups). * + Pairs of variables that are significantly different $(p<0.05)$.

\section{Sample preparation}

Femoral heads were wrapped in sterile gauze soaked in phosphate buffered saline, vacuum sealed into plastic bags and stored frozen at $-20^{\circ} \mathrm{C}$ until required. A transverse slice of bone, about $10 \mathrm{~mm}$ thick, was taken from the distal femur of patients undergoing an above the knee amputation and stored in the same way.

To prepare samples for analysis, stored bones were removed from the freezer and thawed at room temperature. One core of cancellous bone, $9 \mathrm{~mm}$ in diameter and about $10 \mathrm{~mm}$ long, was prepared from the superior aspect of each femoral head as described previously ${ }^{2}$ and left to air dry. They were then powdered using a freezer mill (Model 6750; Glen Creston Ltd, Middlesex, UK) by pre-cooling in liquid nitrogen for 6 minutes followed by milling for 1 minute at 10 impacts per second. The resulting powder was put through a $63 \mu \mathrm{m}$ mesh sieve (BS410/1986; Endocotts Ltd, London, UK) in order to produce a uniform particle size. Powdered samples were stored in tightly sealed glass containers at $-20^{\circ} \mathrm{C}$ until used.

\section{$x$ ray diffraction}

Unit cell dimensions and crystallite size were measured from the prepared bone powder using XRD. A diffraction pattern was recorded from each sample of bone powder using a Stoe Stadi/P diffractometer (Stoe \& Cie GmbH, Darmstadt, Germany) in transmission mode, using $\mathrm{Cu} \mathrm{K}_{\alpha 1}$ radiation (wavelength $0.15406 \mathrm{~nm}$ ). The sample was prepared on a flat plate and rotated about the axis of the beam throughout the period of irradiation to reduce any effects of "graininess" in the sample. Crystallite size was determined using the Scherrer equation ${ }^{27}$ from the full width at half maximum of the 002 scattering peak and the $a$ and $c$ unit cell dimensions from the positions of the 20 strongest scattering peaks. Fitting of the patterns was performed using Stoe FIT software with a squared Lorentzian function. Peak positions were calibrated with a silicon standard.

\section{Thermogravimetric analysis}

A sample of each powder (mass $10.0 \mathrm{mg}$ ) was heated in a thermogravimetric analyser (model TGA/SDTA851; MettlerToledo, Schwerzenbach, Switzerland) linked to a mass spectrometer (Balzers ThermoStar; Balzers Instruments,
Liechtenstein). Samples were enclosed in a $70 \mu \mathrm{L}$ alumina crucible. They were heated at a rate of $10^{\circ} \mathrm{C} / \mathrm{min}$ up to a maximum of $1500^{\circ} \mathrm{C}$, in a stream of dry air delivered from a regulated cylinder (BOC Gases; Guildford, Surrey, UK). MS was used to monitor for species with relative molecular masses of 18 (water) and $44\left(\mathrm{CO}_{2}\right)$. A sample of $\mathrm{CuSO}_{4} \cdot 5 \mathrm{H}_{2} \mathrm{O}$ (BDH Laboratory Supplies, Poole, UK) was heated between every two bone samples, and the presence of the expected water peaks was used to ensure the capillary leading from the furnace to the mass spectrometer was not blocked. An empty crucible was heated under the same conditions as the samples and the resulting thermogram subtracted from those obtained from the samples to enable buoyancy effects to be corrected.

\section{Statistical methods}

Results from the three groups were compared using analysis of variance or its non-parametric equivalent, Kruskal-Wallis analysis of variance on ranks, where data were not normally distributed. Normality of the distributions was assessed using the Kolmogorov-Smirnov test with $p=0.05$. Mean values and their associated standard deviations are shown for data that are normally distributed, otherwise values are medians. Ages are shown as median and maximum and minimum. Pairwise comparisons of groups following analysis of variance were performed using Tukey's test. All tests were performed using SigmaStat software (version 2.01; SPSS Inc, Chicago, IL, USA).

\section{RESULTS}

\section{$x$ ray diffraction}

The mean values of the unit cell dimensions and the crystallite size are shown in table 2 . No significant difference was found in the unit cell dimensions between either the OA or the OP patient groups and the control group (analysis of variance $\mathrm{p}=0.12$, for both $a$ and $c$ ). Similarly, no significant differences were found between median values of crystallite size ( $p=0.36$, analysis of variance on ranks). Two of the OP samples had large crystals, (crystallite sizes of $37.9 \mathrm{~nm}$ and $39.9 \mathrm{~nm}$ ) that were outliers to the normal distribution, but no reason for these unusual values was evident.

\section{Thermogravimetric analysis}

A typical trace of mass as a function of time, from TGA in air, and the corresponding MS recordings of water and carbon dioxide are shown in fig 1 . The traces from all three patient groups were similar. The first mass loss, at about $100^{\circ} \mathrm{C}$, was due to adsorbed water and was not considered further. The baseline dry mass was recorded after this loss had occurred for determining fractional compositions. The decomposition of the organic component occurred between 300 and $500^{\circ} \mathrm{C}$, and gave rise to one water peak and two, often imperfectly resolved, $\mathrm{CO}_{2}$ peaks in the MS trace. The change in slope of the mass trace also indicated that mass was lost in two stages. There was a significant difference $(\mathrm{p}<0.001$, two way

Table 2 Unit cell dimensions and crystallite size for bone samples from the various patient groups

\begin{tabular}{lccc}
\hline & OA & Control & \multicolumn{1}{l}{ OP } \\
\hline a dimension $(\mathrm{nm})$ & 0.9415 & 0.9413 & 0.9417 \\
& $(0.0003)$ & $(0.0002)$ & $(0.0005)$ \\
c dimension $(\mathrm{nm})$ & 0.6882 & 0.6881 & 0.6883 \\
Crystallite size $(\mathrm{nm})$ & $(0.0002)$ & $(0.0002)$ & $(0.0003)$ \\
& $21.8(1.9)$ & 22.4 & 22.4 \\
& & $(2.3)$ & $(21.6$ to 24.2) \\
\hline
\end{tabular}

Values shown are mean (SD) except where data were not normally distributed, in which case the median ( 25 to $75 \%$ ) values are shown. 

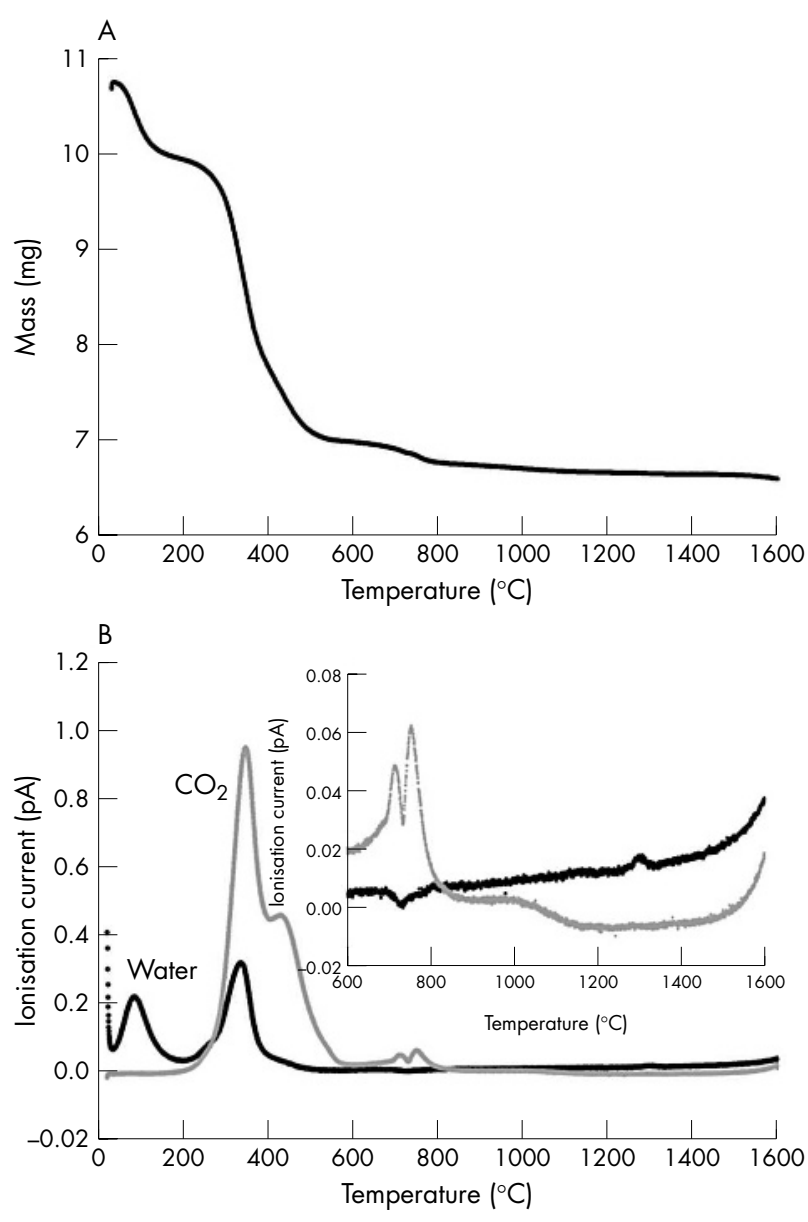

Figure 1 A typical trace, from a control sample, of $(a)$ the mass as a function of temperature, measured using TGA, and (b) the corresponding traces of water and carbon dioxide recorded on the mass spectrometer (the inset is an enlarged version of the traces above $600^{\circ} \mathrm{C}$ ). All samples were air dried, so no account was taken of the first mass lost, which can be explained by loss of residual water. Organic components are lost between $200-550^{\circ} \mathrm{C}$. Carbonate was evolved in two stages: a doublet peak between $700-800^{\circ} \mathrm{C}$ then an extended loss up to $1100^{\circ} \mathrm{C}$. Final decomposition of the mineral occurs at about $1300^{\circ} \mathrm{C}$.

analysis of variance) between the group means for the water peak and the first $\mathrm{CO}_{2}$ peak $\left(339(5){ }^{\circ} \mathrm{C} v 349(9){ }^{\circ} \mathrm{C}\right)$, indicating that these are not being driven off simultaneously. No significant difference was found between patient groups. The position of the second $\mathrm{CO}_{2}$ peak was found to be slightly higher in the OA group than the control group $\left(436(11)^{\circ} \mathrm{C} v\right.$ $\left.428(7){ }^{\circ} \mathrm{C}\right)(\mathrm{p}=0.04)$, indicating that there may be a small increase in the temperature at which this mass is lost in the OA group. The masses of the organic components lost during this process from each patient group are shown in table 3 ,

Table 3 Masses attributed to organic and mineral components as a percentage of the dry mass, and carbonate as a fraction of the mineral, for each patient group

\begin{tabular}{llll}
\hline & OA & Control & OP \\
\hline Mineral & $67.2(3.0)$ & $68.5(3.6)$ & $70.1(3.6)$ \\
Organic & $32.8(3.0)$ & $31.5(3.6)$ & $29.9(3.6)$ \\
Carbonate & $7.15(0.79)$ & $7.63(0.76)$ & $7.49(0.59)$ \\
\hline
\end{tabular}

with OA bone containing a greater organic fraction than normal or OP.

There was a statistically significant difference between the groups for the mineral and organic components $(p=0.038)$ but not for the carbonate content of the mineral $(p=0.16)$ (one way analysis of variance).

The mineral content was derived from the mass remaining at about $600^{\circ} \mathrm{C}$ after all the organic material had been removed. This was lowest in the OA and greatest in the OP bone, with the control samples in between (table 3). At temperatures greater than $600^{\circ} \mathrm{C}$, the mineral starts to decompose. The peaks in the $\mathrm{CO}_{2}$ trace, which occurred at about $700-800^{\circ} \mathrm{C}$, arise from carbonate being driven out of the crystal structure. ${ }^{28} 29$ The two peaks occurred at about $700^{\circ} \mathrm{C}$ and $760^{\circ} \mathrm{C}$ in all three groups. Corresponding to one of these there was absorption of water, shown by the dip in the water trace at about $700^{\circ} \mathrm{C}$ (fig lb, inset). There was then an extended loss of $\mathrm{CO}_{2}$ up to a temperature of about $1100^{\circ} \mathrm{C}$, as can be seen from the inset MS trace in fig $\mathrm{lb}$, and a loss of water at about $1300^{\circ} \mathrm{C}$. Assuming the $\mathrm{CO}_{2}$ arises from breakdown of carbonate in the mineral, the mass of carbonate can be calculated from the change in mass between $600^{\circ} \mathrm{C}$ and $1200^{\circ} \mathrm{C}$ multiplied by 1.36 (the relative molecular masses of $\mathrm{CO}_{3}$ and $\mathrm{CO}_{2}$ ) and expressed as a percentage of the mineral mass. The resulting carbonate contents are shown in table 3, but any differences were not significant.

\section{DISCUSSION}

This study confirms previous results that reported a reduction in the mineral content of cancellous bone from the hip of patients with osteoarthritis. ${ }^{24}{ }^{14}$ Studies of bone from the iliac crest have reported higher mineral contents by density fractionation of cortical bone ${ }^{30}$ and back scattered electron microscopy. ${ }^{31}$ These data indicate that site and bone type may be important factors governing the changes caused by OA. The slightly higher temperature required to obtain carbon dioxide from the OA bone, shown by the second low temperature peak in the MS trace, suggests a greater stability of the organic matrix, but the origins of this are unknown. The results also show that ashing at $600^{\circ} \mathrm{C}$, as performed previously, ${ }^{2}$ is a reliable way of determining mineral content, as no carbonate is lost from the mineral until higher temperatures are reached. There are few previous studies of human bone using thermogravimetry, and the stages of material loss and the carbonate content found here are similar to those reported elsewhere. ${ }^{32}{ }^{33}$ The smaller mineral content of OA bone accords with the lower hardness and, by implication, stiffness, found by indentation testing, ${ }^{34}$ but otherwise the lack of differences provides no evidence for disease related processes in the mineral phase.

These data are from the bulk material and provide a basis for further studies in which heterogeneities on a microscopic scale may be explored in more detail. Studies using Fourier transform infrared microscopy on human OP bone ${ }^{35}$ and ovariectomised cynomolgus macaques, ${ }^{36}$ an animal model of the disease, have indicated that OP bone mineral has an increased crystallinity and a higher ratio of carbonate to phosphate. These studies used thin sections of bone and recorded spectra from highly localised regions and it may be that in our study, where the bone was homogenised, these subtle changes are masked.

Carbonate starts to be lost from the mineral at around $650^{\circ} \mathrm{C}$ as shown by the double peak plus an absorption of water in fig 1. The origin of the double peak is unclear, but the strong water absorption would support that at least one of these peaks corresponds to loss of carbonate on a hydroxyl site (A site carbonate), picking up water to maintain the hydroxyapatite structure. ${ }^{37}$ Total decomposition of the 
mineral (to the non-hydroxyapatite phases) is heralded by the water loss at $\sim 1300^{\circ} \mathrm{C}$ (fig 1). Carbonate can substitute for either hydroxyl (A site) or phosphate (B site) groups in carbonate hydroxyapatite (CHA) but is known to affect the unit cell dimensions: in B site CHA, a decreases and $c$ increases, whereas in A site CHA, the opposite is true. The unit cell dimensions measured, however, are the same as those reported for pure hydroxyapatite. ${ }^{38}$ This lack of change in dimensions may indicate that there is a balance between $\mathrm{A}$ and B site substitution. This view is supported by the TGAMS results in which the double peak is followed by a small, but steady, loss of carbonate from $800^{\circ} \mathrm{C}$ up to $1200^{\circ} \mathrm{C} .{ }^{29}$

In conclusion, these results confirm the hypomineralisation of cancellous bone from the femoral head in OA. They also show that the mineral in cancellous bone is the same in both OA and OP and in individuals without either of these disorders. Furthermore, the mineral comprises a carbonate substituted hydroxyapatite in which the carbonate appears to be distributed over both the possible sites of substitution.

\section{ACKNOWLEDGEMENTS}

We thank the Engineering and Physical Sciences Research Council for financial support of this project (GR/L67066) and the Medical Research Council for a Senior Fellowship for R M Aspden. We are grateful to Dr I R Gibson for allowing us to benefit from his considerable knowledge of biological apatites, the Orthopaedic Surgeons of Grampian University Hospitals Trust for kindly donating tissues from their patients, and L A Bestwick and B Paterson for expert technical assistance.

\section{Authors' affiliations}

L D Mkukuma, R M Aspden, Department of Orthopaedic Surgery, University of Aberdeen, Aberdeen AB25 2ZD, UK

C T Imrie, J M S Skakle, Department of Chemistry, University of Aberdeen, Aberdeen AB25 2ZD, UK

D W L Hukins, Department of Bio-Medical Physics and Bio-Engineering, University of Aberdeen, Aberdeen AB25 2ZD, UK

D W L Hukins, Current address: School of Engineering, Mechanical Engineering, University of Birmingham, Edgbaston, Birmingham B15 $2 \mathrm{TT}$, UK

\section{REFERENCES}

1 Hasegawa K, Turner CH, Recker RR, Wu E, Burr DB. Elastic properties of osteoporotic bone measured by scanning acoustic microscopy. Bone 1995; 16:85-90.

2 Li B, Aspden RM. Composition and mechanical properties of cancellous bone from the femoral head of patients with osteoporosis or osteoarthritis. J Bone Miner Res 1997:12:641-51.

3 Li B, Aspden RM. Mechanical and material properties of the subchondral bone plate from the femoral head of patients with osteoarthritis or osteoporosis. Ann Rheum Dis 1997; 56:247-54.

4 Li B, Aspden RM. Material properties of bone from the femoral neck and the calcar femorale of patients with osteoporosis or osteoarthritis. Osteoporos Int 1997:7:450-6.

5 Zioupos P, Aspden RM. Density, material quality and quantity issues in OP cancellous bone. In: Prendergast PJ, Lee TC, Carr AJ, eds. Proceedings of the 12th Conference of the European Society of Biomechanics. Dublin: Royal Academy of Medicine in Ireland, 2000, 327.

6 Bailey AJ, Knott L. Molecular changes in bone collagen in osteoporosis and osteoarthritis in the elderly. Exp Gerontol 1999;34:337-51.

7 Dequeker J, Mokassa L, Aerssens J. Bone density and osteoarthritis. J Rheumatol 1995:22:98-100.

8 Aspden RM, Scheven BAA, Hutchison JD. Osteoarthritis is a systemic disorder involving stromal cell differentiation and lipid metabolism. Lancet 2001;357:1118-20

9 Ding M. Age variations in the properties of human tibial trabecular bone and cartilage. Acta Orthop Scand Suppl 2000;292:1-45.
10 Fazzalari NL, Darracott J, Vernon-Roberts B. Histomorphometric changes in the trabecular structure of a selected stress region in the femur in patients with osteoarthritis and fracture of the femoral neck. Bone 1985;6:125-33.

11 Fazzalari NL, Forwood MR, Smith K, Manthey BA, Herreen P. Assessment of cancellous bone quality in severe osteoarthrosis: Bone mineral density, mechanics, and microdamage. Bone 1998;22:381-8.

12 Burr DB. The importance of subchondral bone in osteoarthrosis. Curr Opin Rheumatol 1998; 10:256-62.

13 Eckstein F, Milz S, Anetzberger H, Putz R. Thickness of the subchondral mineralized tissue zone (SMZ) in normal male and female and pathological patellae. J Anat 1998;192:81-90.

14 Grynpas MD, Alpert B, Katz I, Lieberman I, Pritzker KPH. Subchondral bone in osteoarthritis. Calcif Tissue Int 1991;49:20-6.

15 Lereim P, Goldie IF. Relationship between morphologic features and hardness of the subchondral bone of the medial tibial condyle in the normal state and in osteoarthritis and rheumatoid arthritis. Arch Orthop Unfallchir 1975;81:1-11.

16 Li B, Marshall D, Roe M, Aspden RM. The electron-microscope appearance of the subchondral bone plate in the human femoral head in osteoarthritis and osteoporosis. J Anat 1999;195:101-10.

17 Gevers G, Dequeker J, Martens M, Van Auderkerke R. Biomechanical characteristics of iliac crest bone in elderly women according to osteoarthritis grade at the hand joints. J Rheumatol 1989;16:660-3.

18 McPherson R, Gane N, Bastow TJ. Structural characterization of plasmasprayed hydroxylapatite coatings. J Mater Sci Mater Med 1995;6:327-34.

19 Lazic S, KatanicPopovic J, Zec S, Miljevic N. Properties of hydroxyapatite crystallized from high temperature alkaline solutions. J Crystal Growth 1996; 165:124-8.

20 Mayer I, Cohen H, Voegel JC, Cuisinier FJG. Synthesis, characterization and high temperature analysis of Al-containing hydroxyapatites. J Crystal Growth 1997; 172:219-25.

21 Layani JD, Mayer I, Cuisinier FJG. Carbonated hydroxyapatites precipitated in the presence of Ti. J Inorg Biochem 2000;81:57-63.

22 Abdelfattah WI, Nour FA. Thermal-expansion application to assess calcination of bovine hydroxyapatite. Thermochimica Acta 1993;218:465-75

23 Beevers CA, Mclntyre DB. The atomic structure of fluor-apatite and its relation to that of tooth and bone material. Mineralogical Magazine 1946;27:254-7.

24 Ellies LG, Nelson DG, Featherstone JD. Crystallographic structure and surface morphology of sintered carbonated apatites. J Biomed Mater Res 1988;22:541-53.

25 Handschin RG, Stern WB. Crystallographic and chemical analysis of human bone apatite (Crista lliaca). Clin Rheumatol 1994;13(Suppl 1):75-90.

26 Rey C, Beshah K, Griffin R, Glimcher MJ. Structural studies of the mineral phase of calcifying cartilage. J Bone Miner Res 1991;6:515-25.

27 Klug HP, Alexander LE. X-ray diffraction procedures. New York: John Wiley \& Sons, 1954

28 Ivanova TI, Frank-Kamenetskaya OV, Kol'tsov AB, Ugolkov VL. Crystal structure of calcium-deficient carbonated hydroxyapatite. Thermal decomposition. J Solid State Chem 2001;160:340-9.

29 Suetsugu Y, Tanaka J. Crystal growth of carbonate apatite using a $\mathrm{CaCO} 3$ flux. J Mater Sci Mater Med 1999;10:561-6.

30 Raymaekers G, Aerssens J, van den Eynde R, Peeters J, Geusens P, Devos P et al. Alterations in the mineralisation profile and osteocalcin concentrations in osteoarthritic iliac crest bone. Calcif Tissue Int 1992;51:269-75.

31 Boyde A, Jones SJ, Aerssens J, Dequeker J. Mineral density quantitation of the human cortical iliac crest by backscattered electron image analysis: variations with age, sex, and degree of arthritis. Bone 1995;16:619-27.

32 Bigi A, Cojazzi G, Panzavolta S, Ripamonti A, Roveri N, Romanello M et al. Chemical and structural characterization of the mineral phase from cortical and trabecular bone. J Inorg Biochem 1997;68:45-51.

33 Peters F, Schwarz K, Epple M. The structure of bone studied with synchrotron $\mathrm{X}$-ray diffraction, $\mathrm{X}$-ray absorption spectroscopy and thermal analysis. Thermochimica Acta 2000;361:131-8.

34 Coats AM, Zioupos P, Aspden RM. Material properties of subchondral bone from patients with osteoporosis or osteoarthritis by microindentation testing and electron probe microanalysis. Calcif Tissue Int 2003;73:66-71.

35 Paschalis EP, Betts F, DiCarlo E, Mendelsohn R, Boskey AL. FTIR microspectroscopic analysis of human iliac crest biopsies from untreated osteoporotic bone. Calcif Tissue Int 1997:61:487-92.

36 Luppen CA, Smith E, Spevak L, Boskey AL, Frenkel B. Bone morphogenetic protein-2 restores mineralization in glucocorticoid-inhibited MC3T3-E osteoblast cultures. J Bone Miner Res 2003;18:1186-97.

37 el Feki H, Rey C, Vignoles M. Carbonate ions in apatites: infrared investigations in the upsilon $4 \mathrm{CO} 3$ domain. Calcif Tissue Int 1991;49:269-74.

38 Young RA, Holcomb DW. Variability of hydroxyapatite preparations. Calcif Tissue Int 1982;34:S17-32. 